Jahangirnagar University J. Biol. Sci. 7(2): 65-77, 2018 (December)

\title{
Insights into the bioactive compounds, antioxidant potential and TLC profiling of different extracts of Tomato plants
}

\author{
Sium Ahmed, Faisal Bin Rahman, Shawon Ahmed and \\ Abdullah Mohammad Shohael* \\ Department of Biotechnology and Genetic Engineering, Jahangirnagar University, \\ Savar, Dhaka-1342, Bangladesh
}

\begin{abstract}
Tomato (Solanum lycopersicum L.) is a widely cultivated vegetable crop worldwide and its consumption is increasing day by day. The only edible part of tomato plant is its fruit. Therefore, the residual tomato plant parts are considered as waste after fruit collection despite some portion of it is used as livestock feed and in the production of fertilizer. Moreover, due to the consumption issue, much of the research is focused on tomato fruit rather than other plant parts. Bioactive compounds can be present in any part of the plant and can be isolated and recovered. Therefore, tomato plant may be useful as a source of bioactive compounds. Our study focuses on the phytochemical constituents and bioactive compounds that are present in different parts of the tomato plant that were being less studied before. Qualitative phytochemical tests were performed to identify the presence of different bioactive compounds. Saponins, tannins, glycosides, phenols, alkaloids, flavonoids and resins are present in significant amount. Total phenol, total flavonoids, total tannin, and total protein content were measured quantitatively. Leaf samples showed higher concentrations of bioactive compounds than roots and stem. Highest total phenol content $(66.43 \mathrm{mg} / \mathrm{g})$, total flavonoids content $(28.00 \mathrm{mg} / \mathrm{g})$, total tannin content $(7.36 \mathrm{mg} / \mathrm{g})$ and total protein content $(26.55 \mathrm{mg} / \mathrm{g}$ ) was found from the leaf water extract. DPPH scavenging assay was performed to find the antioxidant potential and positive results were found. Thin layer chromatography (TLC) was also employed to check the constituents. Our study found several spots for different samples and their retention factors $\left(\mathrm{R}_{\mathrm{f}}\right)$ were evaluated.
\end{abstract}

Key words: Antioxidants, Phytochemicals, Tomato, TLC.

\section{INTRODUCTION}

Tomato (Solanum lycopersicum L.) is one of the most popular vegetables consumed throughout the world. Botanically, a tomato can be considered as a fruit, because it has the ovary along with the seeds of a flowering plant. However, it is best regarded as a culinary vegetable as the sugar contents of tomato are much less than culinary fruits (Davies et al., 1981). Tomato is a popular crop because of its year-round availability and various health benefits. It is a good source of ascorbic acid, folic acid, vitamin A and C, carotenoids and other beneficiary nutrients. According to the USDA National Nutrient Database, tomatoes contain an impressive amount of vitamin $\mathrm{A}$, vitamin $\mathrm{C}$, and vitamin $\mathrm{K}$, as well as significant amounts of vitamin B6, folate, and thiamine (Bhowmik et al., 2012). They are also a good source of potassium, manganese, magnesium, phosphorus, and copper. They have dietary fiber and protein, as well as a number of organic compounds like lycopene that contribute to their health benefits (Dorais et al., 2008).

* Corresponding author. E-mail: amshohael@juniv.edu 
Phytochemicals are natural bioactive compounds produced by plants that provide support other than growth and reproduction. They also act as protective agents against external stress and pathogenic attack (Chew et al., 2011). These bioactive compounds have various health benefits including antimicrobial, anti-inflammatory, cancer preventive, antidiabetic and antihypertensive effects. The most important of these bioactive constituents of plants are alkaloids, flavonoids, tannins, phenolic compounds etc. (Kumar et al., 2015).

An antioxidant is a molecule that inhibits the oxidation of other molecules. When the formation of free radicals overtakes the antioxidant defense system, the free radicals start attacking the cell and resulting in several physiological disorders like Alzheimer's disease, cancer, atherosclerosis, diabetes, (Nasrin et al., 2016).

Tomato is consumed in both raw and cooked form as well as processed foods like juices, drinks, sauces, ketchups, salads, purees. Nowadays, tomatoes are growing in countries all over the world and there are thousands of cultivars and varieties. Around 130 million tons of tomato is produced globally each year where 88 million are for the fresh market and the remaining go into processing industries. According to FAOSTAT, Bangladesh ranked 47th worldwide as a producer of tomato. In the year 2016, the area of cultivation was about 27,342 ha with the production of about 368,121 tons (FAOSTAT, 2017).

Tomato is typically cultivated for the purpose of harvesting its fruit for human consumption. The other plant parts are discarded or used as livestock feed which accounts for very little economic return. Recently, residual plant parts are also been considered as a useful element because of the bioactive compounds they contain (Sagar et al., 2018).

The aim of this study was to investigate the presence of phytochemicals in the plant extracts obtained from roots, stem, and leaves and their quantification. The research also armed to find out the antioxidant potential as well as the Thin Layer Chromatographic profiling to evaluate the phytochemical composition.

\section{MATERIALS AND METHODS}

Chemicals and reagents: All chemicals and reagents used in this study were of analytical grade. Aluminum chloride, (+)-Catechin, Potassium iodide, DPPH (2,2diphenyl-1-picrylhydrazyl), Gallic acid were purchased from Sigma Aldrich, USA. Glacial acetic acid was purchased from Scharlau, Spain. Tannic acid was purchased from Loba Chemie, India. Bradford reagent was purchased from Biobasic Canada. Ethanol, Methanol, Fehling A and B, Sodium hydroxide, Sodium nitrite were bought from Merck, Germany. Folin-Ciocalteu reagent was purchased from SRL, India. Sodium carbonate, Chloroform, Iodine were bought from Alfa Aesar, UK. Hexane was bought from Daejung chemicals, South Korea. Ethyl acetate was bought from Duksun pure chemicals, South Korea. 
Plant material: The experiments were conducted at the Plant Biotechnology and Genetic Engineering Laboratory, Department of Biotechnology and Genetic Engineering, Jahangirnagar University, Dhaka-1342, Bangladesh (2353'14” N 90¹5'56” E). The tomato plants (Solanum lycopersicum L.) of variety Ratan were used in this study. The seeds were collected from the local market and planted on the seedbed. 30 days old healthy seedlings were planted in the experimental field located on departmental garden. The plots were maintained according to the standard tomato production management system. 60 days old plants were collected for the preparation of samples.

Preparation of Extract: The plant materials (leaf, stem, and root) were shade dried and powdered in a mechanical grinder. The powdered material $(10 \mathrm{~g})$ were taken in conical flasks with ethanol, methanol, and water as solvent and kept them in a shaker for 3 days at room temperature. The extracts were filtered through Whatman no. 1 filter paper and filtered organic solvents were concentrated using an evaporator, and finally, stock solutions of extracts $(10 \mathrm{mg} / \mathrm{mL})$ were prepared.

Qualitative Phytochemical Analysis: The freshly prepared crude extracts were qualitatively tested for the presence of secondary metabolites especially Carbohydrates, saponins, tannins, glycosides, phenols, coumarins, alkaloids, flavonoids, resins and terpenoids through the following methods.

Carbohydrates: $1 \mathrm{~mL}$ of different extracts were taken into test tubes to which equal volume of Fehling's A and Fehling's B were added. The tubes were heated at $65^{\circ} \mathrm{C}$ in a water bath for 10-15 min. Red brick precipitate indicates the presence of carbohydrates (Fehling, 1849).

Saponins: $2 \mathrm{~mL}$ of distilled water added to $1 \mathrm{~mL}$ of extracts and then shaken for $5 \mathrm{~min}$. The presence of $1 \mathrm{~cm}$ foam for $10 \mathrm{~min}$ indicates the presence of saponin (Kumar et al., 2009).

Tannins: $.5 \mathrm{~mL}$ of extracts were mixed with $1 \mathrm{~mL}$ of distilled water, and then 4-5 drops of $1 \%$ ferric chloride were added. Blue color and the greenish black color indicate the presence of gallic tannin and cathecholic tannin respectively (Ahamed et al., 2017).

Glycosides: $1 \mathrm{~mL}$ of extracts were mixed with $1 \mathrm{ml}$ of glacial acetic acid. Then 5-6 drops of $1 \%$ ferric chloride solution was added. Brown color ring produced at the top indicate glycoside's presence (Ahamed et al., 2017).

Phenols: $1 \mathrm{ml}$ of ethanol was added to $1 \mathrm{ml}$ of extracts. Then 6-7 drops of $1 \%$ ferric chloride solution was added to each tube. Formation of the green, blue, purple color indicates the presence of Phenol (Soloway et al., 1952).

Coumarins: $1 \mathrm{ml}$ of extract was added with $1.5 \mathrm{ml}$ of $10 \% \mathrm{NaOH}$. The chemical reaction will produce a yellow color and indicate the presence of coumarin (Ugochukwu et al., 2013). 
Alkaloids: In $1 \mathrm{ml}$ of extract, 4-6 drops of Wagner's reagents [1.27gm of Iodine and $2 \mathrm{gm}$ of potassium iodide in $100 \mathrm{ml}$ of water] was added. The Radish brown precipitate indicates the presence of Alkaloid (Rizk, 1982).

Flavonoids: $3-4$ drops of $20 \% \mathrm{NaOH}$ solution was added in $2 \mathrm{ml}$ of extract. The intense yellow color formed and become colorless when 4-5 drops of diluted $\mathrm{HCl}$ was added. This indicates the presence of Flavonoids (Ugochukwu et al., 2013).

Resins: $1 \mathrm{~mL}$ of extracts were taken into test tubes. Few drops of acetic anhydride were added to each tube. Finally, $1 \mathrm{~mL}$ of concentrated $\mathrm{H}_{2} \mathrm{SO}_{4}$ was added carefully. The presence of yellow to orange color confirmed the presence of resins (Iqbal et al., 2015).

Terpenoids: $5 \mathrm{~mL}$ of extracts were taken into test tubes and mixed with $2 \mathrm{~mL}$ of chloroform. Then concentrated $\mathrm{H}_{2} \mathrm{SO}_{4}$ was added to each tube. The appearance of reddish-brown coloration at the interface indicated the presence of terpenoids (Sheel et al., 2014).

Determination of total phenolic content: The total phenolics content of the extracts was estimated according to the method described previously (Shohael et al., 2006). $0.5 \mathrm{~mL}$ aliquots of extracts and standards of different concentrations were mixed with $2.5 \mathrm{~mL}$ tenfold diluted Folin-Ciocalteu reagent and $2.5 \mathrm{~mL} 7.5 \%$ sodium carbonate. Then they are kept for $30 \mathrm{~min}$ at $25^{\circ} \mathrm{C}$. The absorbance was measured at $765 \mathrm{~nm}$ in a UV-visible spectrophotometer (T60 UV-Visible Spectrophotometer, PG Instruments Ltd., United Kingdom). The concentration of phenol was determined gallic acid as standard. Total phenolic content was expressed as milligrams of Gallic Acid equivalent (mg GAE)/g extract.

Determination of total flavonoid content: Total flavonoid content was determined following the method of Sakanaka et al., (2005) modified by Shohael et al., (2006). Briefly, $0.25 \mathrm{~mL}$ of plant extract or (+)-Catechin standard solution was mixed with 1.25 $\mathrm{mL}$ of distilled water, followed by addition of $75 \mu \mathrm{L}$ of a $5 \%$ sodium nitrite solution. After $6 \mathrm{~min}, 0.150 \mathrm{ml}$ of a $10 \%$ aluminum chloride solution was added, and the mixture was allowed to stand for a further $5 \mathrm{~min}$ and then $0.5 \mathrm{ml}$ of $1 \mathrm{M}$ sodium hydroxide was added. The mixture was brought to $2.5 \mathrm{ml}$ with distilled water and mixed well. The absorbance was measured immediately at $510 \mathrm{~nm}$ in a UV-visible spectrophotometer (T60 UV-Visible Spectrophotometer, PG Instruments Ltd., United Kingdom). The concentration of flavonoids was determined using (+)-Catechin as standard. The concentration of flavonoids was expressed as milligram Catechin equivalent (mg CE)/g extract.

Determination of total tannin content: The tannins were determined using the Folinciocalteu reagent as described previously (Amorim et al., 2008). Briefly, $0.1 \mathrm{ml}$ of the sample extract is added with $7.5 \mathrm{ml}$ of distilled water. Then $0.5 \mathrm{~mL}$ of Folin-ciocalteu reagent and $1 \mathrm{~mL}$ of $35 \%$ sodium carbonate solution were added. Total volume was adjusted to $10 \mathrm{~mL}$ by adding distilled water. The mixture was incubated at room 
temperature for $30 \mathrm{~min}$ and the absorbance was measured at $725 \mathrm{~nm}$ in a UV-visible spectrophotometer (T60 UV-Visible Spectrophotometer, PG Instruments Ltd., United Kingdom). Blank was prepared with water instead of the sample. A set of standard solutions of tannic acid is read against a blank. The concentration of tannin was determined using tannic acid as standard. The concentration of tannin was expressed as milligram Tannic Acid equivalent (mg TAE)/g extract.

Determination of total protein content: Total proteins were estimated according to the method described by Bradford (Bradford, 1976). $0.1 \mathrm{ml}$ of different extract were taken into test tubes and then $0.9 \mathrm{ml}$ Bradford reagent was added and incubated for $2 \mathrm{~min}$. The absorbance was measured at $595 \mathrm{~nm}$ in a UV-visible spectrophotometer (T60 UV-Visible Spectrophotometer, PG Instruments Ltd., United Kingdom). The concentration of protein was determined using Bovine Serum Albumin (BSA) as standard. The concentration of protein was expressed as milligram Bovine Serum Albumin equivalent (mg BSAE)/g extract.

DPPH free radical scavenging activity: DPPH (2,2-diphenyl-1-picrylhydrazyl) Free radical scavenging activity was carried out using the method described previously (Kabir et al., 2016). Different concentrations $(800,400,200,100,50 \mu \mathrm{g} / \mathrm{mL})$ of extract were dissolved in methanol. $3 \mathrm{~mL}$ of a $0.004 \%$ methanol solution of DPPH was added to each test tube. The mixture was incubated for $30 \mathrm{~min}$ in dark condition. The absorbance was measured at $517 \mathrm{~nm}$ in a UV-visible spectrophotometer (T60 UV-Visible Spectrophotometer, PG Instruments Ltd., United Kingdom). The percent inhibition activity was calculated from $\left[\left(A_{C}-A_{S}\right) / A_{S}\right] \times 100$, where $A_{C}$ is the absorbance of the control and $A_{S}$ is the absorbance of the sample. The inhibition curves were prepared and the half maximal inhibitory concentration (IC50) values were calculated using linear regression analysis.

Thin layer chromatographic (TLC) analysis: Extract of the different sample was subjected to TLC studies. For the TLC analysis, the dimensional ascending method was used (Ahamed et al., 2017). $20 \times 20 \mathrm{~cm}$ TLC plate coated with silica gel 60G F254 (Merck, India), was cut with a scissor in $14 \times 3 \mathrm{~cm}$ shape. The plate was then marked with the pencil softly $1.5 \mathrm{~cm}$ far from both bottom and top. Glass capillaries were used to spot the sample on the TLC plate on the pencil marked bottom line. Then it was placed in the fume hood to dry the plate and loaded the sample again until a dark spot is obtained. Then the solvent Hexane: Ethyl acetate: Acetic acid (4:4:2) about $20 \mathrm{ml}$ was taken in the chamber. The plate was placed in the chamber lining on the top. After the run, plates were dried in the fume hood and then used to detect the spots.

Detection of the spot: All the plates were dried and detected the spots with the help of UV light at $254 \mathrm{~nm}$ and $366 \mathrm{~nm}$ (Ahamed et al., 2017). The movement of the active compound was expressed by the retention factor $\left(\mathrm{R}_{\mathrm{f}}\right)$.

Retention factor $\left(\mathrm{R}_{\mathrm{f}}\right)=\begin{aligned} & \text { Diatance traveled by solute } \\ & \text { Diatance traveled by zolvent }\end{aligned}$ 
Statistical analysis: Significant differences among mean values were compared by Tukey's honestly significant difference (HSD) test at a level of significance of $p \leq 0.05$. All data were displayed as the mean \pm standard error of the mean at least three independent biological replications. The statistical analysis was performed using Statistical Package for Social Science software (SPSS, version 16.0, IBM Corporation, NY).

\section{RESULTS AND DISCUSSION}

Preparation of Extract: After evaporation of the solvent, the obtained dry extract weight was measured to obtain the extraction yield. Results are depicted in Table 1.

Table 1. Percentage yield $(\%)$ of different samples after extraction

\begin{tabular}{c|c|c|c}
\hline Plant part & Solvent & Extract weight $(\mathbf{g})$ & Percentage yield (\%) \\
\hline \multirow{2}{*}{ Root } & Ethanol & 1.17 & 11.7 \\
& Water & 0.58 & 5.8 \\
\multirow{3}{*}{ Stem } & Ethanol & 1.77 & 17.7 \\
& Water & 1.84 & 18.4 \\
\multirow{2}{*}{ Leaf } & Ethanol & 1.29 & 12.9 \\
& Water & 1.41 & 14.1 \\
\hline
\end{tabular}

Qualitative Phytochemical Analysis: For the pharmacological discovery of novel drugs, the required information's regarding the chemical constituents are generally obtained by the qualitative phytochemical screening of plant extracts. Our result showed that the extracts contain a significant amount of resins, terpenoids, coumarins, glycosides, and phenols while alkaloids, tannins, saponins, and carbohydrates are also present in considerable amount. However, different extracts of the same sample showed different results to the tests. The results of the qualitative estimation of phytochemicals are given in Table 2.

Table 2. Screening results of bioactive compounds of different extracts

\begin{tabular}{c|c|c|c|c|c|c}
\hline Compound & $\begin{array}{c}\text { Ethanol } \\
\text { extract } \\
\text { (Root) }\end{array}$ & $\begin{array}{c}\text { Water } \\
\text { extract } \\
(\text { Root })\end{array}$ & $\begin{array}{c}\text { Ethanol } \\
\text { extract } \\
(\text { Stem })\end{array}$ & $\begin{array}{c}\text { Water } \\
\text { extract } \\
(\text { Stem })\end{array}$ & $\begin{array}{c}\text { Ethanol } \\
\text { extract } \\
\text { (Leaf) }\end{array}$ & $\begin{array}{c}\text { Water } \\
\text { extract } \\
\text { (Leaf) }\end{array}$ \\
\hline Carbohydrates & ++ & - & ++ & + & + & - \\
Saponins & + & ++ & + & + & + & + \\
Tannins & + & + & + & + & + & + \\
Glycosides & + & + & + & + & ++ & ++ \\
Phenols & + & + & + & + & ++ & ++ \\
Coumarins & + & ++ & ++ & + & + & + \\
Alkaloids & ++ & + & + & + & ++ & + \\
Flavonoids & + & ++ & + & ++ & ++ & +++ \\
Resins & +++ & + & ++ & + & ++ & ++ \\
Terpenoids & + & ++ & - & + & +
\end{tabular}


Determination of total phenolic content: Plants contain different types of phenolic derivatives. Phenolic compounds are natural antioxidants that may occur in all parts of the plant and function as antibiotics and natural pesticides (Silva-Beltrán et al., 2015). Fig. 1 shows the total phenol contents of the different extracts. Highest phenol content was found for leaf water extract $(66.43 \mathrm{mg} \mathrm{GAE} / \mathrm{g}$ of extract) and lowest phenol content was found for root water extract (34.78 $\mathrm{mg} \mathrm{GAE} / \mathrm{g}$ of extract). Leaf extract exhibits a high amount of phenol than roots and stem. A similar result was found by Silva-Beltrán et al. (2015). The order of amount for total phenolic content of different extracts are as followsWater extract (leaf) $>$ Ethanol extract (Leaf) $>$ Ethanol extract (Stem) $>$ Ethanol extract (Root)> Water extract (Stem)> Water extract (Root).The high accumulation of phenol in leaves may be due to the direct exposure to light and UV radiation (Silva-Beltrán et al., 2015).

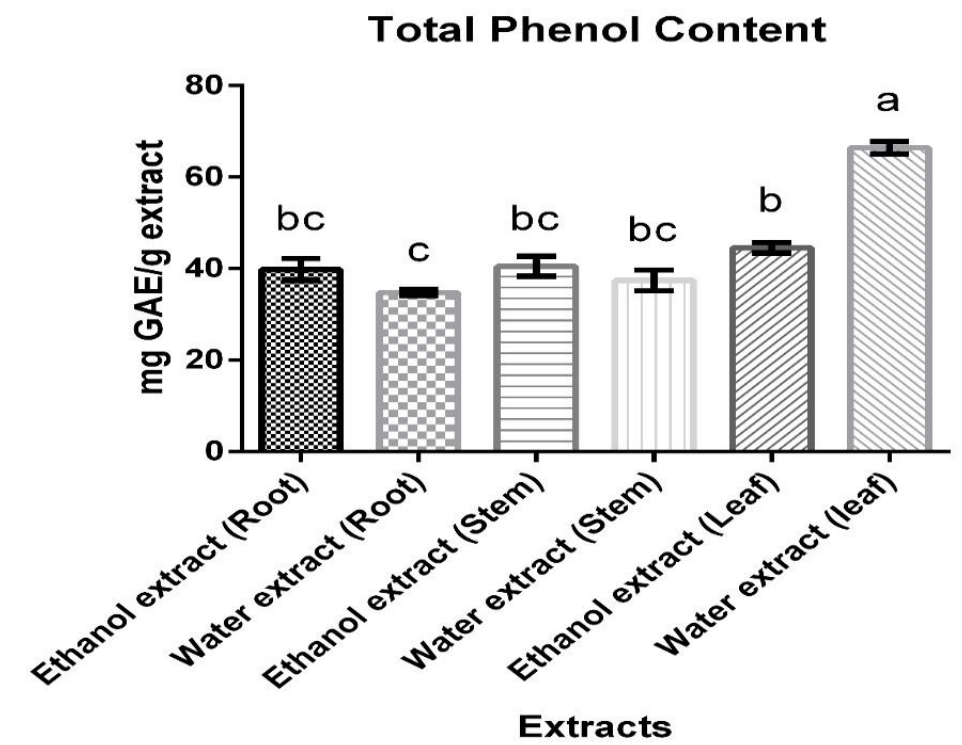

Fig. 1. Total phenol content present in different extracts expressed as mg Gallic Acid Equivalent/ $g$ of extract. Means with the same letter within each column are not significantly different according to Tukey's HSD tests $(P<0.05)$

Determination of total flavonoid content: The Flavonoids are widely distributed in plants and responsible for many functions. Flavonoids are the most important plant pigments for flower coloration. In higher plants, flavonoids are involved in UV filtration, symbiotic nitrogen fixation, and floral pigmentation. They may also act as chemical messengers, physiological regulators, and cell cycle inhibitors. The total flavonoids concentration for different extracts were shown in Fig. 2. Leaf extracts showed more flavonoid content than root and stem where leaf water extract was found to be highest (28.00 mg CE/g of extract). Root water extract also showed very similar flavonoids content to the leaf ethanol extract. The lowest flavonoids content was found for stem ethanol extract (17.37 mg CE/g of extract). 


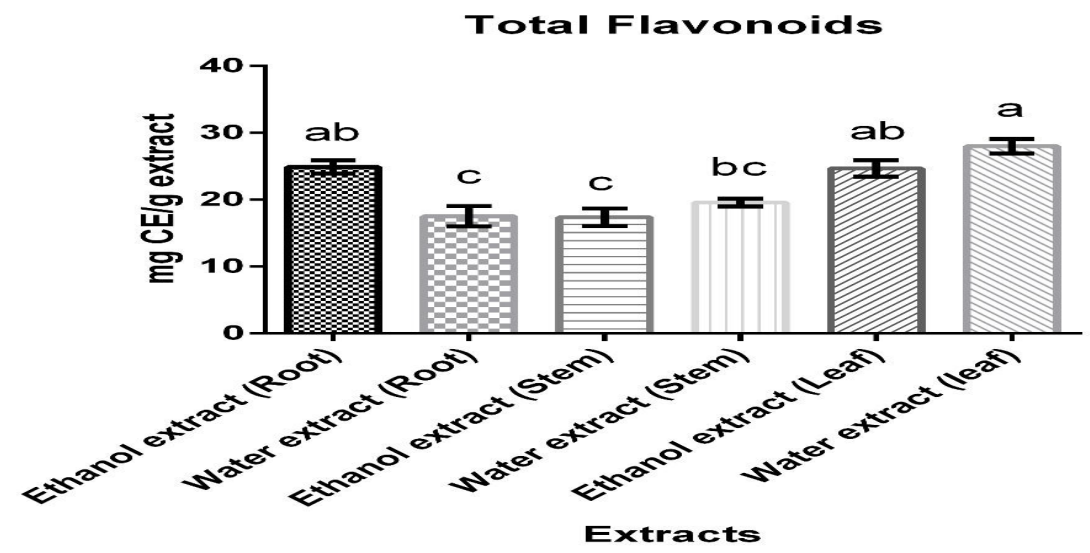

Fig. 2. Total flavonoid content present in different extracts expressed as mg Catechin Equivalent/ $g$ of extract. Means with the same letter within each column are not significantly different according to Tukey's HSD tests $(P<0.05)$

Silva-Beltrán et al. (2015) found lower flavonoids content in root extract than stem extract. However, our study found very similar flavonoids content in root and stem. The order of amount for total flavonoids content of different extracts are as follows- Water extract (leaf) $>$ Ethanol extract (Root) $>$ Ethanol extract (Leaf)> Water extract (Stem)> Water extract (Root)> Ethanol extract (Stem).

Determination of total tannin content: The result of total tannin is shown in Fig. 3. According to the results, the total tannin content in different extracts is very low. Among them, the leaf water extract showed the highest tannin content (7.36 mg TAE/g of extract) and root ethanol extract showed the lowest tannin content $(5.31 \mathrm{mg} \mathrm{TAE} / \mathrm{g}$ of extract). The order of amount for total tannin content of different extracts are as follows- Water extract (leaf)> Ethanol extract (Leaf)> Water extract (Stem)> Water extract (Root)> Ethanol extract (Stem)> Ethanol extract (Root).

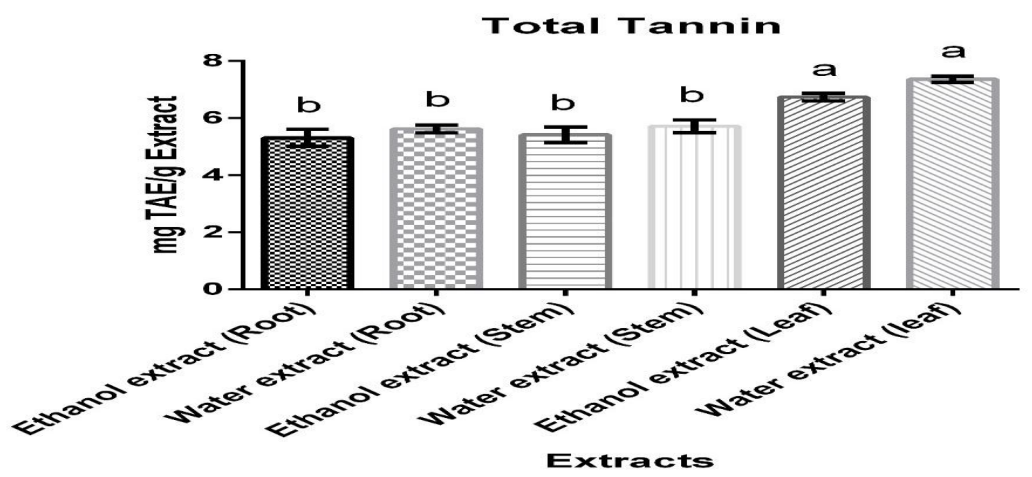

Fig. 3. Total tannin content present in different extracts expressed as mg Tannic Acid Equivalent/ $g$ of extract. Means with the same letter within each column are not significantly different according to Tukey's HSD tests $(P<0.05)$ 
Tannins are natural polyphenols ubiquitously distributed in plants, such as vegetables, fruits, and seeds. In the roots, it acts as a protection against pathogens. In the stem, tannin is present in the areas of active growth where it regulates the growth of the tissues. In the leaves, tannin provides an astringent flavor which reduces the appetite of herbivorous animals and insects and thus represents a natural line of defense (Swain, 1977).

Determination of total protein content: The result of total protein is shown in Fig. 4. According to the results, the total protein content in different extracts is very low. Among them, the leaf water extract showed the highest protein content $(26.55 \mathrm{mg} \mathrm{BSAE} / \mathrm{g}$ of extract) and stem water extract showed the lowest protein content $(20.42 \mathrm{mg} \mathrm{BSAE} / \mathrm{g}$ of extract). The order of amount for the total protein content of different extracts are as follows- Water extract (leaf)> Ethanol extract (Leaf)> Water extract (Root) $>$ Ethanol extract $($ Stem $)>$ Ethanol extract $($ Root $)>$ Water extract $($ Stem).

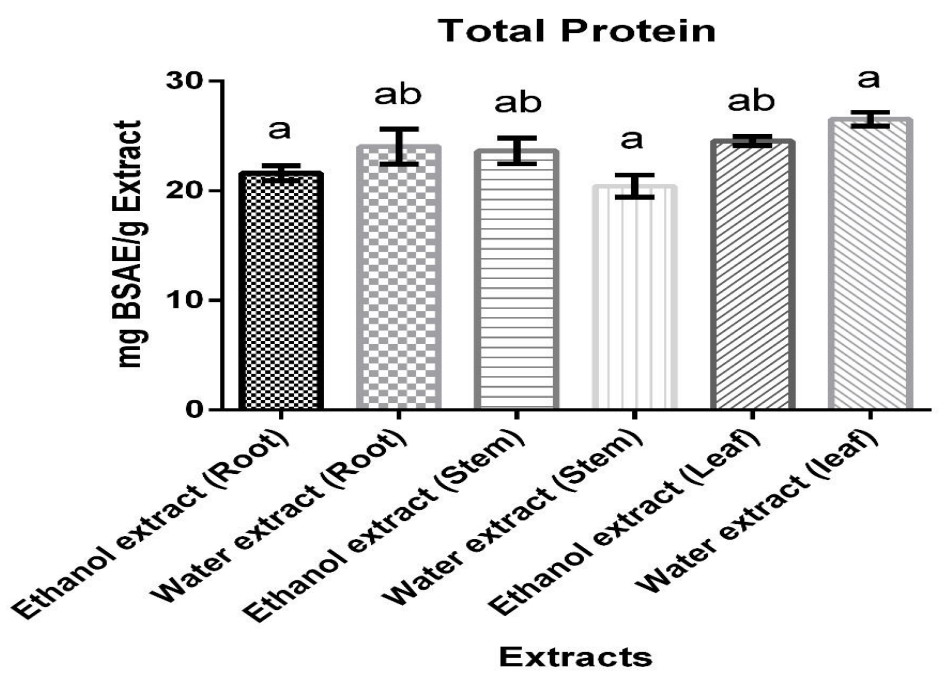

Fig. 4. Total protein content present in different extracts expressed as mg Bovine Serum Albumin Equivalent/ $g$ of extract. Means with the same letter within each column are not significantly different according to Tukey's HSD tests $(P<0.05)$

DPPH free radical scavenging activity: We evaluated the antioxidant activity of the extracts by evaluating DPPH scavenging assays and the results are reported by percent scavenging activity. The half inhibition concentration (IC50) for free radicals was also calculated. Results for the DPPH scavenging activity of different extracts are shown in Fig. 5. The extract showed a dose-dependent radical scavenging effect in DPPH assay. The highest scavenging activity was found for leaf ethanol extract $(78.38 \%)$ at $800 \mu \mathrm{g} / \mathrm{mL}$ extract concentration and lowest scavenging activity was found for stem water extract (43.32\%) $800 \mu \mathrm{g} / \mathrm{mL}$ extract concentration. For IC50 value, the lowest value was obtained $(235.58 \mu \mathrm{g} / \mathrm{mL})$ for leaf ethanol extract and the highest value was obtained $(765.86 \mu \mathrm{g} / \mathrm{mL})$ for stem water extract. 


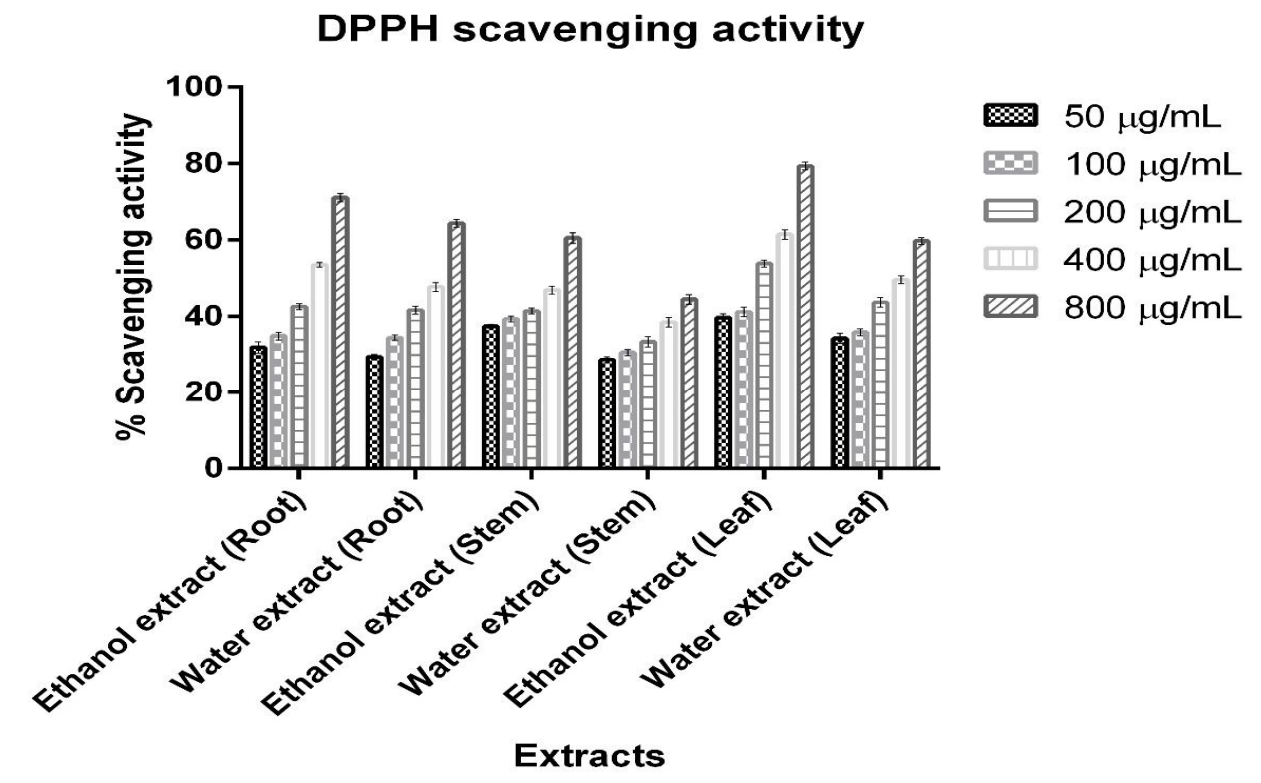

Fig. 5. DPPH free radical scavenging activity of different extracts

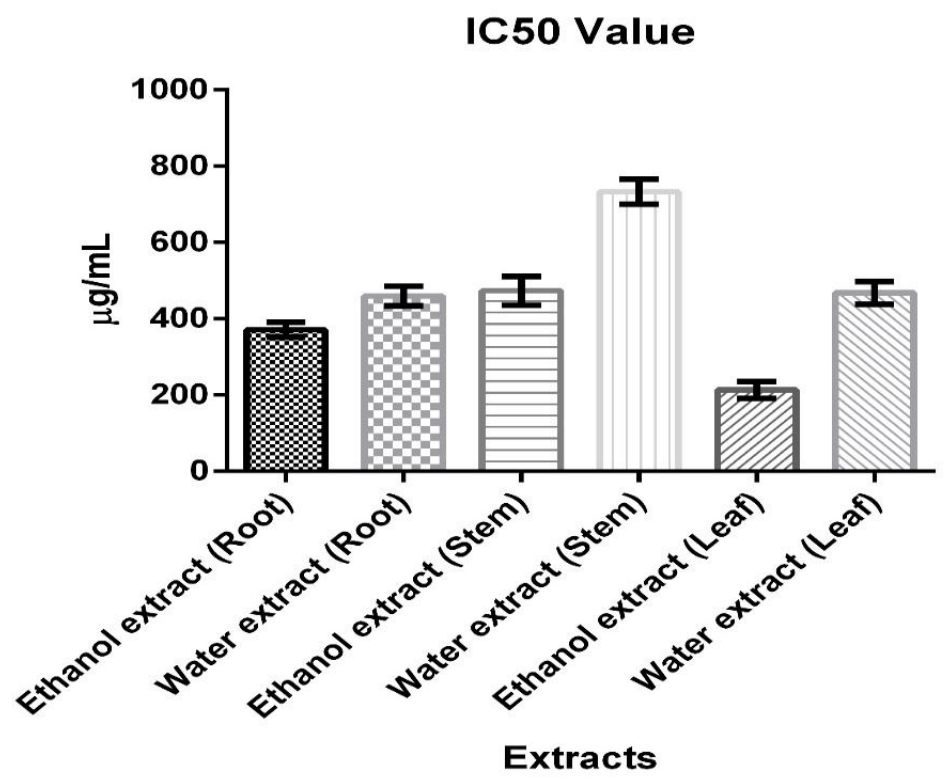

Fig. 6. The half inhibition concentration (IC50) of different extracts as determined from the DPPH free radical scavenging activity 
The stable DPPH radical model is a widely used and precise method for the evaluation of free radical scavenging activity. DPPH is a stable free radical and accepts an electron or hydrogen radical to become a stable diamagnetic molecule. Antioxidant on interaction with DPPH both transfer electron or hydrogen atom to DPPH and thus neutralizing its free radical character and convert it to 1-1, diphenyl-2- picryl hydrazine and the degree of discoloration indicates the scavenging activity. Hence DPPH is usually used as a substance to evaluate the antioxidant activity. Results of this study suggest that the plant extract contain phytochemical constituents that are capable of donating hydrogen to a free radical to scavenge the potential damage.

Thin layer chromatographic (TLC) analysis: TLC of all extracts were carried out to confirm its nature by analyzing TLC chromatograms and to identify active ingredients from the extracts which are shown in Table 3. The highest number of spots (3) was found for leaf ethanol extract and the lowest number of spots (1) was found for root water extract. The retention factors were also shown in Table 3.

Table 3. Thin Layer Chromatographic (TLC) profiles of different extracts

\begin{tabular}{cccc}
\hline Extracts & No. of spot detected & $\mathbf{R}_{\mathbf{f}}$ \\
\hline Ethanol extract (Root) & 2 & 0.45 \\
Water extract (Root) & 1 & 0.48 \\
Ethanol extract (Stem) & 2 & 0.50 \\
Water extract (Stem) & 2 & 0.94 \\
& & 0.29 \\
Ethanol extract (Leaf) & 3 & 0.68 \\
& & 0.29 \\
Water extract (Leaf) & \multirow{2}{*}{2} & 0.59 \\
& & 0.22 \\
& & 0.15 \\
\end{tabular}

TLC profiling of all extracts gives an impressive result that directing towards the presence of a number of phytochemicals. Various phytochemicals give different $\mathrm{Rf}$ values. This variation in $\mathrm{Rf}$ values of the phytochemicals provides a very important clue in the understanding of their polarity and suggests a selection of an appropriate solvent system for separation of pure compounds. The selection of an appropriate solvent system for particular plant extracts can only be achieved by analyzing the Rf values of compounds in the different solvent system (Sharma et al., 2013).

Therefore, the result shown here is not a constant indicator of the compounds present. However, more intense research should be employed to evaluate the potential of the tomato plant as a source of bioactive compounds that may be useful in different aspect of pharmaceutical, industrial and biotechnological applications. 
Acknowledgments: This research was partially supported by the research grant provided by GARE (Grant for Advanced Research in Education), Ministry of Education, University Grant Commission research grant to Jahangirnagar University, Jahangirnagar University research grant, Special Allocation in Science and Technology of Ministry of Science and Technology, Bangladesh. We are thankful to our lab members, who provided opinion and expertise that greatly assisted this research.

\section{REFERENCES}

Ahamed, T., Rahman, S.K.M. and Shohael, A.M. 2017. Thin layer chromatographic profiling and phytochemical screening of six medicinal plants in Bangladesh. Int. J. Biosci. 11(1): 131140.

Amorim, E.L.C., Nascimento, J.E., Monteiro, J.M., Peixoto Sobrinho, T.J.S., Araújo, T.A.S. and Albuquerque, U.P. 2008. A simple and accurate procedure for the determination of tannin and flavonoid levels and some applications in ethnobotany and ethnopharmacology. Funct. Ecosyst. Communities. 2(1): 88-94.

Bhowmik, D., Kumar, K.P.S., Paswan, S. and Srivastava, S. 2012. Tomato-a natural medicine and its health benefits. J. Pharmacogn. Phytochem. 1(1): 33-43.

Bradford, M.M. 1976. A rapid and sensitive method for the quantitation of microgram quantities of protein utilizing the principle of protein-dye binding. Anal. Biochem. 72(1-2): 248-54.

Chew, Y.L., Chan, E.W.L., Tan, P.L., Lim, Y.Y., Stanslas, J. and Goh, J.K. 2011. Assessment of phytochemical content, polyphenolic composition, antioxidant and antibacterial activities of Leguminosae medicinal plants in Peninsular Malaysia. BMC Complement. Altern. Med. 11(1): 12.

Davies, J.N., Hobson, G.E. and McGlasson, W.B. 1981. The constituents of tomato fruit - the influence of environment, nutrition, and genotype. C R C Crit. Rev. Food. Sci. Nutr. 15(3): 205-80.

Dorais, M., Ehret, D.L. and Papadopoulos, A.P. 2008. Tomato (Solanum lycopersicum) health components: from the seed to the consumer. Phytochem. Rev. 7(2): 231.

FAOSTAT, F. 2017. Statistical data. Food and Agriculture Organization of the United Nations, Rome.

Fehling, H. 1849. Die quantitative Bestimmung von Zucker und Stärkmehl mittelst Kupfervitriol. Justus Liebigs Ann. Chem. 72(1): 106-13.

Iqbal, E., Salim, K.A. and Lim, L.B.L. 2015. Phytochemical screening, total phenolics and antioxidant activities of bark and leaf extracts of Goniothalamus velutinus (Airy Shaw) from Brunei Darussalam. J. King Saud Univ. 27(3): 224-32.

Kabir, H., Shah, M., Hossain, M.M., Kabir, M., Rahman, M. and Hasanat, A. 2016. Phytochemical screening, Antioxidant, Thrombolytic, $\alpha$-amylase inhibition and cytotoxic activities of ethanol extract of Steudnera colocasiifolia K. Koch leaves. J. Young Pharm. 8(4).

Kumar, A., Ilavarasan, R., Jayachandran, T., Decaraman, M., Aravindhan, P. and Padmanabhan, N. 2009. Phytochemicals investigation on a tropical plant, Syzygium cumini from Kattuppalayam, Erode district, Tamil Nadu, South India. Pakistan J. Nutr. 8(1): 83-5.

Kumar, G.P., Anilkumar, K.R. and Naveen, S. 2015. Phytochemicals Having Neuroprotective Properties from Dietary Sources and Medicinal Herbs. Pharmacog. J. 7(1): 1-17.

Nasrin, M.S., Jesmin, F., Rahman, M.M. and Alam M.F. 2016. Seed germination potential, Phytochemical analysis and antioxidant activities of two tomato varieties. Int. J. Biosci. 8(1): 63-76. 
Rizk, A.M. 1982. Constituents of plants growing in Quatar. 1. A chemical survey of sixty plants. Fitoterapia. 53: 35-44.

Sagar, N.A., Pareek, S., Sharma, S., Yahia, E.M. and Lobo, M.G. 2018. Fruit and Vegetable Waste: Bioactive Compounds, Their Extraction, and Possible Utilization. Compr. Rev. Food Sci. Food Saf. 17(3): 512-531.

Sakanaka, S., Tachibana, Y. and Okada, Y. 2005. Preparation and antioxidant properties of extracts of Japanese persimmon leaf tea (kakinoha-cha). Food Chem. 89(4): 569-75.

Sharma, V. and Paliwal, R. 2013. Preliminary phytochemical investigation and thin layer chromatography profiling of sequential extracts of Moringa oleifera pods. Int. J. Green Pharm. 7(1).

Sheel, R., Nisha, K. and Kumar, J. 2014. Preliminary phytochemical screening of methanolic extract of Clerodendron infortunatum. IOSR J. Appl. Chem. 7(1): 10-3.

Shohael, A.M., Ali, M.B., Yu, K.W., Hahn, E.J. and Paek, K.Y. 2006. Effect of temperature on secondary metabolites production and antioxidant enzyme activities in Eleutherococcus senticosus somatic embryos. Plant Cell Tissue Organ Cult. 85(2): 219-28.

Silva-Beltrán, N.P., Ruiz-Cruz, S., Cira-Chávez, L.A., Estrada-Alvarado, M.I., Ornelas-Paz, J.D. J. and López-Mata, M.A. 2015. Total phenolic, flavonoid, tomatine, and tomatidine contents and antioxidant and antimicrobial activities of extracts of tomato plant. Int. J. Anal. Chem.

Soloway, S. and Wilen, S.H. 1952. Improved Ferric Chloride Test for Phenols. Anal. Chem.

Swain, T. 1977. Secondary compounds as protective agents. Annu. Rev. Plant Physiol. 28(1): 479501.

Ugochukwu, S.C., Uche, A. and Ifeanyi, O. 2013. Preliminary phytochemical screening of different solvent extracts of stem bark and roots of Dennetia tripetala G. Baker. Asian J. Plant. Sci. Res. 3(3): 10-3. 